\title{
RESEARCH OPPORTUNITIES ABOUT MEASURING AGILITY IN SOFTWARE DEVELOPMENT: A CONSTRUCTIVIST PERSPECTIVE
}

\author{
OPORTUNIDADES DE PESQUISA SOBRE MENSURAÇÃO DE AGILIDADE NO \\ DESENVOLVIMENTO DE SOFTWARE: UMA PERSPECTIVA CONSTRUTIVISTA
}

\author{
Rogério Tadeu de Oliveira Lacerda \\ Professor of the postgraduate program in management at UFSC \\ Federal University of Santa Catarina \\ rogerlacerda@gmail.com \\ Ewerton Sacco Calvetti \\ Master of management - UFSC \\ Federal University of Santa Catarina \\ escalvetti@gmail.com \\ Mayara Lucia Bernardes \\ $\mathrm{PhD}$ student in the postgraduate program in management - PPGA/UFSC \\ Federal University of Santa Catarina \\ mayaralbernardes@gmail.com \\ Júlia Fraga Cargnin da Silveira \\ Graduate Student in Executive Secretariat - UFSC \\ Federal University of Santa Catarina \\ julia.f.c.s10@gmail.com
}

\begin{abstract}
This paper investigates research opportunities in an agile software development process according to constructivist performance evaluation lenses, based on a portfolio of 24 scientific articles relevant to the topic. The instrument used to carry out the systemic analysis was the Proknow-C method (Knowledge Development Process - Constructivist). It was observed in the portfolio that the performance evaluation to measure agility in the context of software development has focused practically on critical success factors and on inflexible models that rank in maturity levels, but without clearly evaluating how much agility is employed. This study addresses relevant research opportunities that seek to identify criteria and to build performance scales for measuring agility based on the values and preferences of the decision makers, who wish to implement the agile philosophy, aligned with the specific strategic of the decision makers objectives and using their singular resources, competences and own organizational culture in order to improve their software development process.
\end{abstract}

Keywords: Performance evaluation. Agile software development. Decision aiding. Agility. ProknowC.

\section{Resumo}

Este artigo investiga oportunidades de pesquisa em um processo ágil de desenvolvimento de software sob óticas construtivistas de avaliação de desempenho, com base em um portfólio de 24 artigos científicos relevantes ao tema. $\mathrm{O}$ instrumento utilizado para realizar a análise sistêmica foi o método Proknow-C (Knowledge Development Process - Construttivist). Observou-se no portfólio que a avaliação de desempenho para medir a agilidade no contexto de desenvolvimento de software tem se focado praticamente em fatores críticos de sucesso e em modelos inflexíveis que se classificam em níveis de maturidade, mas sem avaliar claramente quanta agilidade é empregada. Este estudo aborda oportunidades de pesquisas relevantes que buscam identificar critérios e construir escalas de desempenho para medir agilidade a partir dos valores e preferências dos tomadores de decisão, que desejam implementar a filosofia ágil, alinhada com a estratégia específica dos objetivos dos tomadores de decisão e utilizando seus recursos, competências e cultura organizacional próprias para melhorar seu processo de desenvolvimento de software. 
Palavras-chave: Avaliação de desempenho. Desenvolvimento ágil de software. Apoio à decisão. Agilidade. Proknow-C.

\section{Cite como - American Psychological Association (APA)}

Lacerda, R. T, de O., Calvetti, E. S., Bernardes, M. L., \& Silveira, J. F. C. da (2020, maio/ago.). Research opportunities about measuring agility in software development: a constructivist perspective. Revista de Gestao e Projetos (GeP), 11(2), 37-63. https://doi.org/10.5585/gep.v11i2.17947.

\section{Introduction}

Over the decades, agile approaches to software development have been extensively discussed by professionals. These approaches have been increasingly adopted in place of traditional methods, with broad promises involving frequent and rapid deliveries, increased customer satisfaction, empowerment of the development team, increased collaboration between those involved and gaining quality in the product and service (Gandomani \& Nafchi, 2014; Mahnič \& Zabkar, 2008).

Meanwhile, the lean concept, derived from manufacturing, is incorporated into the software area. Thus, reinforcing the agile methods through practices used in lean production in response to customer expectations and requirements. Both approaches are integrated by eliminating waste, dispensing idle resources to engage in other activities, discovering critical points, and consequently adding value to the customer (Baines, Lightfoot, Williams, \& Greenough, 2006; Lacerda, Klein, Fulco, Santos, \& Bittarello, 2017; Petersen \& Wohlin, 2011).
However, agile methods and lean practices should not be confused. Petersen and Wohlin (2011) explain that lean practices provide analysis tools and improvements focused on the entire software development lifecycle, while agile methods prescribe a range of practices to achieve a solution with agility. Therefore, agile methods and lean practices are not substitutes, but actually complementary.

In order to achieve agility and competitive prerogatives in a highly resilient environment, the performance evaluation is fundamental for the company to perform an efficient and effective management. A company using that is capable of reporting the level of performance performed in relation to the planned, assuming the importance of the singularity adopted in research involving the performance evaluation (Kennerley \& Neely, 2002; Melnyk, Bititci, Platts, Tobias, \& Andersen, 2014).

Drawing on Oliveira, Lacerda, Fiates, and Ensslin (2016), Lacerda, Ensslin, and Ensslin (2014), Ensslin, Ensslin, Lacerda, and Matos (2013), Afonso, de Souza, Ensslin, and Ensslin (2012), Landry (1995) and Roy (1993), 
the present study adopts the constructivist world view regarding the performance evaluation in agility in the software development process, much as possible to antecipate and realize it is a process of knowledge construction by decision makers, who seek as much as posible to antecipate and realize the consequences of their decisions, taking into account relevant features of a particular situation. From this point of view, knowledge is built and structured during the activities of identifying, organizing, evaluating and integrating the relevant aspects for adecision maker, making use of ordinal and cardinal scales to evaluate performance in a given context and moment.

In the literature, evaluating the degree of agility, as demonstrated by Gandomani and Nafchi (2014), is subjective, not representing an objective nature, and it is well known that the term agility is perceived and not universally defined.

This research has, hence, the objective of identifying and analyzing research opportunities in an agile software development process according to constructivist performance evaluation lenses, based on a portfolio of 24 scientific articles relevant to the topic.

The composition of the portfolio was obtained from the application of a selective method called ProKnow-C (Knowledge Development Process-Constructivist), proposed by Ensslin, Ensslin, Lacerda, and Tasca (2010). In order to perform the content analysis of the articles selected by this method we apply, the analysis lenses proposed by L. Ensslin, Ensslin, and de Souza (2014), Lacerda et al. (2014) and Marafon, Ensslin, Lacerda, and Ensslin (2012), which are: (i) theoretical filiation; (ii) context singularity; (iii) process of identification of the criteria; (iv) measurement methods (scales); (v) integration of scales (by reference levels); and, (vi) management (diagnosis and improvement).

The rest of the paper is structure as follows. The next section presents theoretical framework, while the section 3 lays out the methodological aligment adopted and the systemic analysis based on the ProKnow-C method. Meanehile, section 4 shows the results and identified research opportunities. A final section with concluding remarks closes the paper.

\section{Theoretical background}

In this section, we will address the concepts related to agility and performance evaluation, which are important for the theoretical background necessary to carry out the systematic analysis.

\subsection{Agile methods}

Over the years, agile approaches have been increasingly frequent in software development, highlighting the agile methods in the practices for achieving agility in the solution (Petersen \& Wohlin, 2011).

Agile software development is a set of principles established by developers, based on 
past practices and experiences, intense communication and collaboration between the development team, customer and business area, minimal documentation and rapid and incremental deliveries (Conforto \& Amaral, 2016; Dingsøyr, Nerur, Balijepally \& Moe, 2012; Misra, Kumar \& Kumar, 2009).

These principles are opposed to the traditional methodology that has a previously defined team, with excess documentation, fixed requirements and unique product delivery. To deal with the challenges of traditional methods, the agile community defined a set of values: (i) individuals and interactions rather than processes and tools; (ii) develop software rather than comprehensive documentation; (iii) customer collaboration rather than contractual negotiations; (iv) response to changes rather than plans (Gren, Torkar, \& Feldt, 2015).

In practice, few organizations are able, psychologically or technically, to immediately adopt the agile software development approach and when adopted, their complete transition may take years. When adopting, it is important for the decision maker to evaluate performance from an agile perspective, noting its relevance when aggregating it to agile methods in the software development process (Qumer \& Henderson-Sellers, 2008b).

\subsection{Performance evaluation}

Performance evaluation is conceptualized as an instrument used to quantify and validate the efficiency and / or effectiveness of the action, presenting the level of performance achieved and comparing it with the planned, important for any business (Kennerley \& Neely, 2002; Melnyk et al., 2014)

In order to identify research opportunities in a performance evaluation approach in the agile software development process and knowing that it is important to add the concept of agility, it is important to consider the different purposes for performance evaluation: evaluate, control, budget, motivate, celebrate success, promote, learn and improve. Among these basic purposes, the most important of them is to improve the performance, or contextualized for this research, to evaluate the degree of agility in a particular company that would allow the manager a better understanding of how this concept is executed in its context and propose gradual improvements to raise the degree of agility in their projects (Behn, 2003).

The epistemological knowledge, addressed in this research follows the classification given by Dias and Tsoukiàs (2003) and Roy (1993) with four distinct approaches that can be applied in performance evaluation: normativist, descriptive, prescriptive and constructivist.

The normativist approach derives from a universal and rational model, allowing to define and analyze the problem according to universally accepted criteria (Dias \& Tsoukiàs, 2003).

The descriptivism is defined as a 
rational model, starting from the observation of how decision makers made their decisions in the past in relation to a result. This approach binds decisions with the quality of results, making use of mathematical models, optimal solutions and statistics, focusing on causal relationships. The normative and descriptive approaches are independent of the person who decides (Dias \& Tsoukiàs, 2003). Roy (1993) calls both approaches realism, without human perception as an element of decision.

Regarding the prescriptive decision approach, Dias and Tsoukiàs (2003), argue that it attempts to answer questions and provide a description of the problems with the aim of assisting in better decision-making information. Roy (1993), addresses the construction of a deductive system from which the researcher must have an understanding of the context to prescribe solutions.

Finally, Dias and Tsoukiàs (2003), describe the constructivist approach as one that constructs models for a specific decisionmaker, and the discussion with stakeholders is part of the process of building understanding in the decision-maker, supporting the whole process of supporting decision. Roy (1993) points out that incoherent responses are opportunities for gradual learning, so that initial data can be discontinued, others may appear, and new questions can be formulated, expanding and generating knowledge, during concept construction, modeling, procedures, and outcomes.

Landry (1995), in a more simplified form, presents three other views on the epistemology of knowledge, in an objectsubject relation: objectivist, subjectivist and constructivist. For the author the objectivist approach is originated from the object, it is up to the subject to discover reality through experiments; the subjectivist is originated from the subject, based on consciousness; and the constructivist is the result of the interaction between object and subject, with the formation of knowledge from the perceptions of the subject, changing the context and reacting.

Given the concepts of decision-making and decision-aiding approaches, Crawford and Pollack (2004), using the soft or hard dichotomy, have named the objectivist approach as hard, of realistic (normativist and descriptivist) philosophy and the subjectivist approach as soft, sustained by prescritivism and constructivism. Thus, the agile approaches, according to the epistemological filiation adopted in this research, were characterized as constructivism, as soft.

\subsubsection{Evaluation criteria}

The evaluation criteria are defined by Keeney (2009) and Keeney (1996) as a statement of something that is achieved within a context, an object and a direction of preference. For this research, it is considered the preference of the decision maker, for being directly responsible for generating changes in the current scenario, with authority.

When defining the evaluation criteria, the list of objectives should be carefully 
examined, aiming to identify hidden objectives that can be discovered through the expansion of the knowledge in the decision maker, as well as determining those that are really important, defining and classifying the points of fundamental and elemental views, always dependent on context. In other words, values and preferences-focused thinking changes the behavior of the company and makes the decision maker closer to what he wants and desires and therefore not restrictive to the alternatives that are presented (Keeney, 1996, 2009; Roy, 1993).

\subsubsection{Performance evaluation in agile methods}

Understands the authors of this research, as well as McCaffery, Taylor, and Coleman (2007) already cited in his work that agile methods are not easily evaluated by predefined software development models and processes such as ISO / IEC 15504, widely known as SPICE (Software Process Improvement and Capability Determination), and CMMI. Although this is possible, as identified during this research the mapping occurrence of some of the agile methods, among them SCRUM and XP (Extreme Programming), for ISO 9001 and levels 2 and 3 of CMMI, also tracing a parallel to levels 4 and 5 .

Process-based models such as those mentioned above cannot guarantee the agility of companies and teams involved in software development because agile methods through their principles focus on people and interactions rather than processes and tools (Fontana, Meyer, Reinehr, \& Malucelli, 2015). Therefore, the authors of this research understand that the practice of such models is incompatible and contradictory, providing scientific studies such as the one proposed here. Corroborating for the same reasons, Gren et al. (2015) does not consider hierarchical models to be a good model for measuring agility in companies.

Exemplifying by means of the scientific articles identified in the bibliographic portfolio, Sidky, Arthur, and Bohner (2007) proposes a multilevel model called SAMI (Sidky Agile Measurement Index), similar to the one applied in the CMMI approach, demonstrating that it is a model that does not present flexibility, forcing the company to adopt a set of practices stipulated in each level. Similarly, Qumer and Henderson-Sellers (2008a, 2008b) propose a model of improvement and agility to evaluate the degree of agility also in a multilevel model inspired by CMMI, making use of the dimensional analytical tool 4-DAT, but reducing The flexibility to have predefined practices at each level, a practice that is desired in agile methods. Other authors, in more recent studies also related in the portfolio, have recognized this problem by looking for new alternatives.

Thus agreeing, in a recent scientific article, Gren et al. (2015) points out in his study that until that period there was no agile maturity model that could be considered reliable, requiring more in-depth studies. The 
author understands that a set of agile predefined practices may not reflect the real meaning of an agile team, highlighting here an opportunity to proceed with future research according to a constructivist approach, where the criteria for performance evaluation of agility in software development process will be defined according to the values and preference of the decision maker, for having the responsibility during a decision-making process.

In fact, what has been observed since previous researches, such as in Gandomani and Nafchi (2014) , few models of agility evaluation have been presented. Even less is the recognition of the singularity of the company and that agility should not always be evaluated in the same way, as carefully examined by Jalali, Wohlin, and Angelis (2014), stating that those responsible must first decide what agility means to the company and then proceed with the best way to evaluate agility.

\section{Methodological procedure}

Aspiring to present to the readers the context of the research design, from the planning phase to obtaining the conclusions, the current section portrays in Figure 1 the methodological alignment.

The nature of the objective of this research is exploratory and descriptive, for seeking knowledge, identifying opinions through the 24 scientific articles of the bibliographic portfolio that scientifically support this research, published in journals and index bases identified in the introductory section, aiming at the discovery and identification of Opportunities, involving literary revisions of an unexplored or wellknown subject, but from a new perspective (Casarin \& Casarin, 2011; Lacerda et al., 2014). 
Figure 1 - Methodological alignment

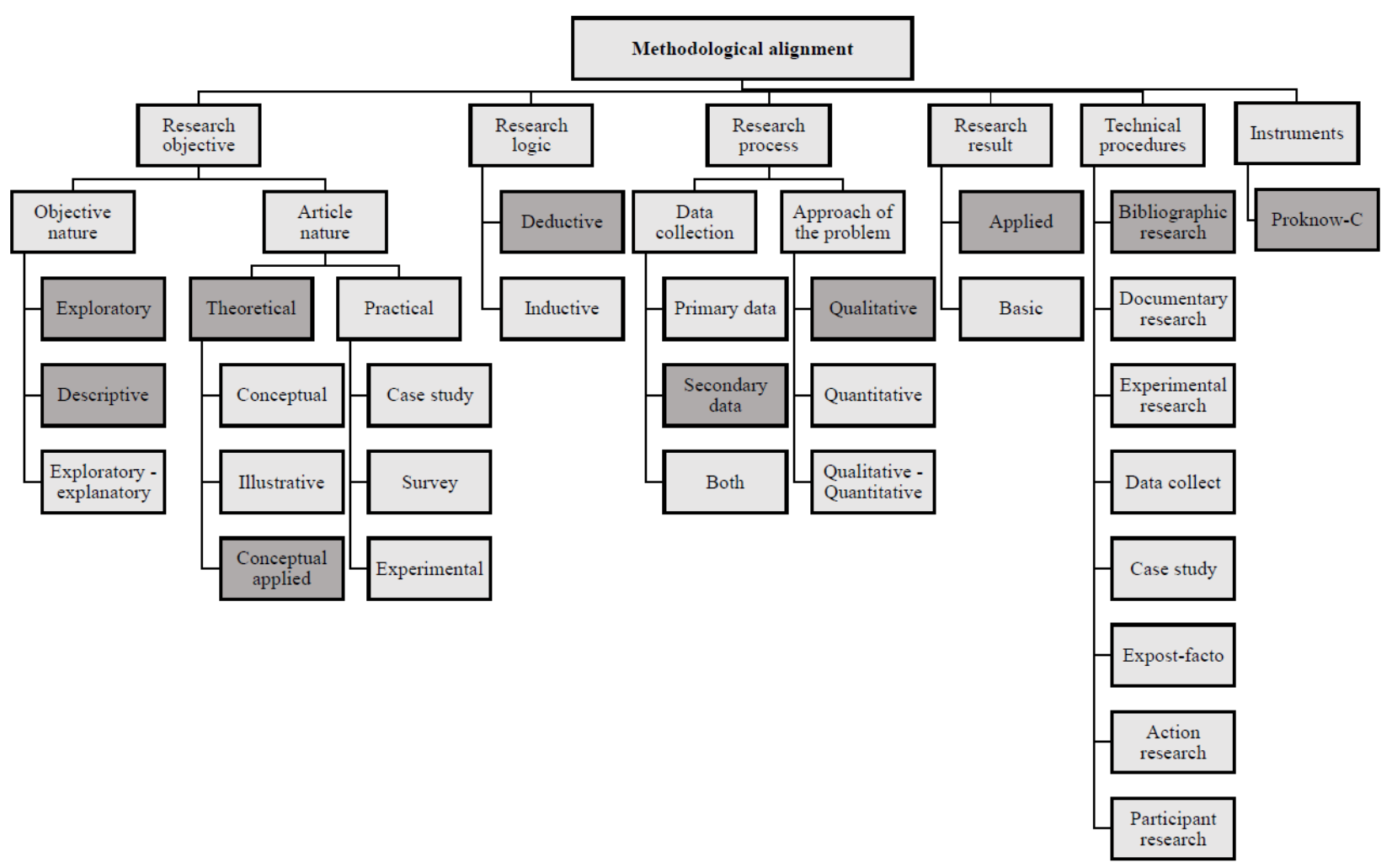

Source: Adapted from Marafon et al. (2012).

This article was classified as theoretical and conceptually applied, since it occurs when adding practical applicability to the definition of a systemic analysis considering the research in a theoretical universe, producing knowledge based on concepts included in its referential (da Rosa, Ensslin, \& Ensslin, 2011; Lacerda et al., 2014).

Regarding the research logic, it was classified as deductive under the justification of reading and deducing the knowledge presented in the bibliographic portfolio, to later develop knowledge about the construction of a systemic analysis of a theoretical referential on the approach of performance evaluation in the agile software development process from the perspective of agility, understanding that knowledge until then is not obscure and has already been identified (da Rosa et al., 2011; Lacerda et al., 2014).

The data collect included only secondary data, since the researchers use data that satisfy the objective of the article when evaluating the compilation of the 24 already identified scientific publications (da Rosa et al., 2011; Lacerda et al., 2014). As a part of the process, a qualitative approach was adopted when analyzing the publications, properly aligned with the research context, since in this type of approach the descriptive nature prevails during the data treatment, not including mathematical and statistical models 
(Casarin \& Casarin, 2011).

Regarding the result, this research is applied by using the generated knowledge in the face of the identified opportunities regarding the topic studied (da Rosa et al., 2011; Lacerda et al., 2014).

The technical procedures used were bibliographic research. It is a bibliographical research because it has been developed from materials already exhibited in periodicals, in accordance with the topic that approaches the evaluation of performance to the methods of agile software development.

As detailed in sub-item 3.2, the instrument used to carry out the systemic analysis was the Proknow-C method (Knowledge Development Process Constructivist), already presented in the introduction. The researchers opted for this method, as had already been shown by L. Ensslin et al. (2014), Lacerda et al. (2014) and Marafon et al. (2012), because it is possible to generate knowledge in the researcher, necessary to the topic addressed, by applying the constructivist approach, considering its worldview and delimitations, raising the initial state of knowledge to a higher level of expansion.

This article merely addresses the systemic analysis step highlighted in Figure 2 which demonstrates the ProKnow-C method. 
Figure 2 - ProKnow-C process steps

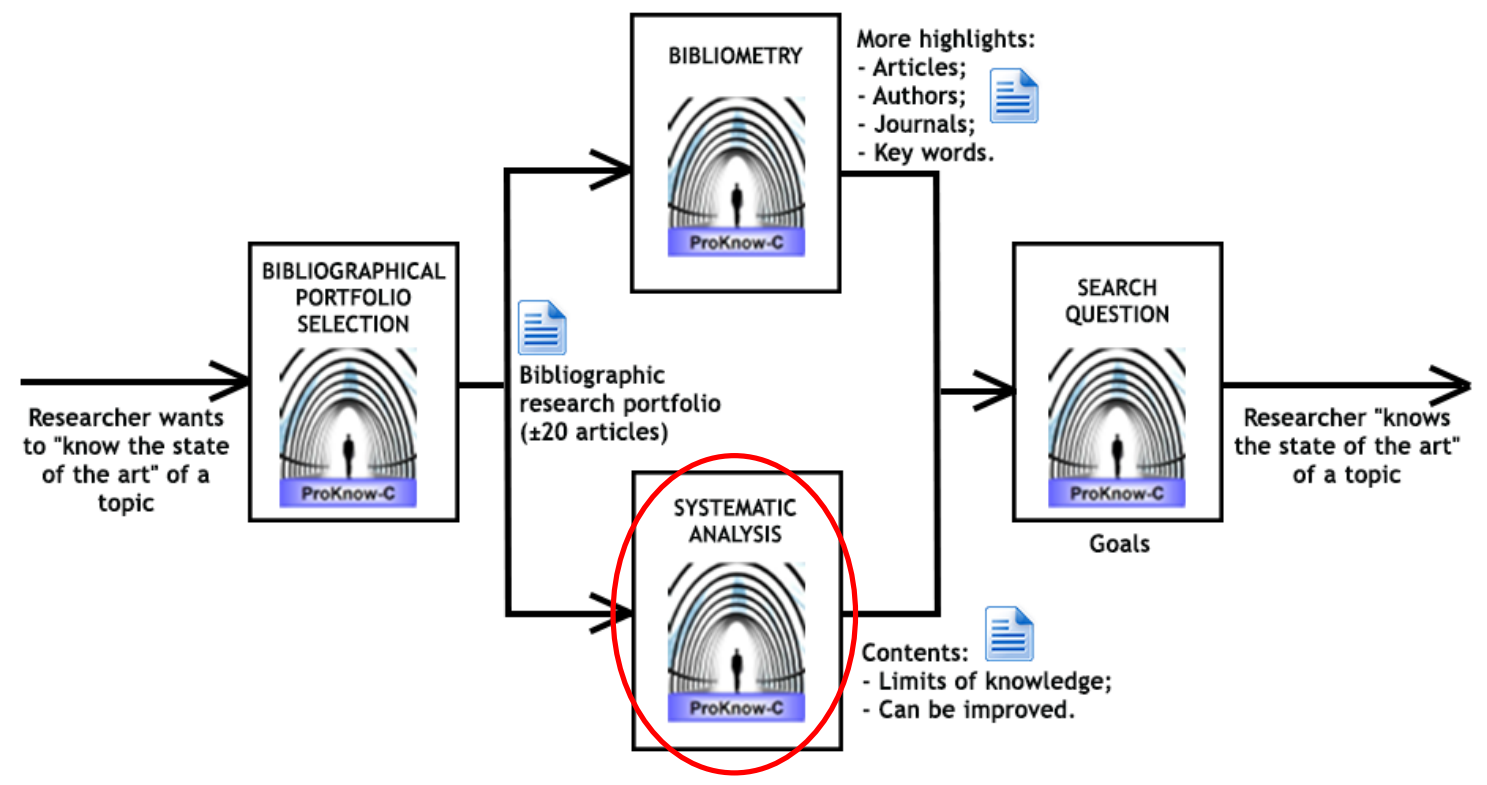

Source: Adapted from Ensslin et al. (2010).

\subsection{Articles selection process}

The process of selection of the 24 scientific articles that compose the bibliographic portfolio representing a significant sample of the topic, allowing an expressive systemic analysis of the state of the art of the researched topic, as mentioned in the introduction of this work, considered the most relevant scientific articles identified through a bibliometric study using the ProKnow-C method, captured from the Scopus and ISI Web of Science databases.

Recognized the origin for the formation of the bibliographic portfolio, to carry out a thorough search of the most relevant scientific articles, we observed the definition of the keywords demonstrated in
Figure 3, with limited knowledge of the researcher at this point in the research. The number of citations of the articles was identified by the Google Scholar tool and by alignment of the title, summary and content with the values and preferences of the researcher. It was identified, in accordance with ProKnow-C, that the article selection process occurred in the following order: (i) research on the scientific bases and defined keywords; (ii) alignment by title; (iii) filter of the most cited articles; (iv) alignment as described in the abstract; (v) incorporation of more recent articles; and, (vi) alignment by the complete reading of the articles. The information about details of this paper selection process, found in Calvetti et al (2019). 
Figure 3 - Keywords

$\begin{array}{llll}\text { Combination 1 } & \text { Measure } & \text { AND } & \text { "Agility in software development" } \\ \text { Combination 2 } & \text { Assessment } & \text { AND } & \text { "Agility in software development" } \\ \text { Combination 3 } & \text { Evaluation } & \text { AND } & \text { "Agility in software development" } \\ \text { Combination 4 } & \text { Appraisal } & \text { AND } & \text { "Agility in software development" } \\ \text { Combination 5 } & \text { Measure } & \text { AND } & \text { "Agile software development" } \\ \text { Combination 6 } & \text { Assessment } & \text { AND } & \text { "Agile software development" } \\ \text { Combination 7 } & \text { Evaluation } & \text { AND } & \text { "Agile software development" } \\ \text { Combination 8 } & \text { Appraisal } & \text { AND } & \text { "Agile software development" } \\ \text { Combination 9 } & \text { Measure } & \text { AND } & \text { "Agile methodology" } \\ \text { Combination 10 } & \text { Assessment } & \text { AND } & \text { "Agile methodology" } \\ \text { Combination 11 } & \text { Evaluation } & \text { AND } & \text { "Agile methodology" } \\ \text { Combination 12 } & \text { Appraisal } & \text { AND } & \text { "Agile methodology" } \\ \text { Combination 13 } & \text { Measure } & \text { AND } & \text { "Software development process" } \\ \text { Combination 14 } & \text { Assessment } & \text { AND } & \text { "Software development process" } \\ \text { Combination 15 } & \text { Evaluation } & \text { AND } & \text { "Software development process" } \\ \text { Combination 16 } & \text { Appraisal } & \text { AND } & \text { "Software development process" }\end{array}$

Source: Authors.

After the search, the articles that established greater academic relevance regarding the performance evaluation approach in the agile software development process under the constructivist perspective, with application of the ProKnow-C method, were selected, limiting themselves to the last 10 years. The literature search was carried out in 2017, however, for this version of the paper, an update was carried out and added to incorporate the references published until August 2020, thus maintaining the current results.

Posteriorly, adding classic articles aligned to the topic, allowing the formation of the bibliographic portfolio presented in Figure 4, making it possible to perform the systemic analysis proposed in this article. The classic articles have been incorporated as part of the ProKnow-C process to support a topic that is rarely addressed by the scientific community when it combines agile methods with performance evaluation. 
Figure 4 - Bibliographic portfolio

Alahyari, H., Svensson, R. B., \& Gorschek, T. (2017). A study of value in agile software development 1 organizations. Journal of Systems and Software, 125, 271-288. doi: 10.1016/j.jss.2016.12.007

2 Basili, V. R., \& Rombach, H. D. (1988). The TAME project: Towards improvement-oriented software environments. IEEE Transactions on software engineering, 14(6), 758-773.

3 Boehm, B. W. (1988). A spiral model of software development and enhancement. Computer, 21(5), 6172.

Choraś, M., Springer, T., Kozik, R., López, L., Martínez-Fernández, S., Ram, P., ... \& Franch, X. (2020).

4 Measuring and Improving Agile Processes in a Small-Size Software Development Company. IEEE Access, 8, 78452-78466.

5 Chow, T., \& Cao, D.-B. (2008). A survey study of critical success factors in agile software projects. Journal of Systems and Software, 81(6), 961-971.

6 Diebold, P., Theobald, S., Wahl, J., \& Rausch, Y. (2019). Stepwise transition to agile: From three agile practices to Kanban adaptation. Journal of Software: Evolution and Process, 31(5), e2167.

7 Fontana, R. M., Meyer, V., Jr., Reinehr, S., \& Malucelli, A. (2015). Progressive Outcomes: A framework for maturing in agile software development. Journal of Systems and Software, 102, 88-108.

8 Gandomani, T. J., \& Nafchi, M. Z. (2014). Agility assessment model to measure Agility degree of Agile software companies. Indian Journal of Science and Technology, 7(7), 955-959.

9 Gren, L., Torkar, R., \& Feldt, R. (2015). The prospects of a quantitative measurement of agility: A validation study on an agile maturity model. Journal of Systems and Software, 107, 38-49.

Gupta, V., Kapur, P. K., Kumar, D., \& Singh, S. P. (2019). Analytical evaluation of agile success factors 10 influencing quality in banking sector. International Journal of Industrial and Systems Engineering, 33(3), 346-373.

11

Jalali, S., Wohlin, C., \& Angelis, L. (2014). Investigating the applicability of Agility assessment surveys: A case study. Journal of Systems and Software, 98, 172-190.

12 Lee, G., \& Xia, W. (2010). Toward agile: an integrated analysis of quantitative and qualitative field data. Management Information Systems Quarterly, 34(1), 7.

13 McCaffery, F., Taylor, P. S., \& Coleman, G. (2007). Adept: A unified assessment method for small software companies. IEEE Software, 24(1), 24-31. 
14

Miranda, E., \& Bourque, P. (2010). Agile monitoring using the line of balance. Journal of Systems and Software, 83(7), 1205-1215.

15

Olszewska, M., Heidenberg, J., Weijola, M., Mikkonen, K., \& Porres, I. (2016). Quantitatively measuring a large-scale agile transformation. Journal of Systems and Software, 117, 258-273.

16

Özcan-Top, Ö., \& Demirors, O. (2019). Application of a software agility assessment model-AgilityMod in the field. Computer Standards \& Interfaces, 62, 1-16.

Patel, C., \& Ramachandran, M. (2009). Story card Maturity Model (SMM): A process improvement

framework for agile requirements engineering practices. Journal of Software, 4(5), 422-435.

18 Paulk, M. C. (2001). Extreme programming from a CMM perspective. IEEE software, 18(6), 19-26.

19

Paulk, M. C., Curtis, B., Chrissis, M. B., \& Weber, C. V. (1993). Capability maturity model, version 1.1. IEEE software, 10(4), 18-27.

20

Qumer, A., \& Henderson-Sellers, B. (2008a). An evaluation of the degree of agility in six agile methods and its applicability for method engineering. Information and software technology, 50(4), 280-295.

21 improvement of agile methods in practice. Journal of Systems and Software, 81(11), 1899-1919.

22

Sidky, A., Arthur, J., \& Bohner, S. (2007). A disciplined approach to adopting agile practices: the agile adoption framework. Innovations in systems and software engineering, 3(3), 203-216.

Tam, C., da Costa Moura, E. J., Oliveira, T., \& Varajão, J. (2020). The factors influencing the success of

23 on-going agile software development projects. International Journal of Project Management, 38(3), 165176.

Tarhan, A., \& Yilmaz, S. G. (2014). Systematic analyses and comparison of development performance and

24 product quality of Incremental Process and Agile Process. Information and Software Technology, 56(5), 477-494.

Source: Authors.

\subsection{Systemic analysis}

The criteria used by the researchers in this performance evaluation in agility in the software development process to carry out the systemic analysis of the presented portfolio considered a world vision, here called analysis lenses, allowing the reaching of objectives, values and preferences of the decision maker, aligned with the paradigm of constructivist decision aiding as the authors Marafon, Ensslin, Lacerda, and Ensslin (2015), Lacerda 
et al. (2014), S. R. Ensslin, Back, Ensslin, and Lacerda (2013) and de Azevedo, Lacerda, Ensslin, Jungles, and Ensslin (2012).

Such analysis lenses, quoted in the introductory section and detailed below, are in accordance with the definition of performance evaluation described by Marafon et al. (2012) in describing it as a process to build knowledge in the decision maker, regarding the specific context that proposes to evaluate, from the perception of the decision maker through activities that identify, organize, measure ordinally and cardinally, making it possible to visualize the impact of actions and management.

These lenses, in the view of the researchers, allow to identify the theoretical filiation of the articles that support this research, the singularity of the context, the identification, measurement and integration of the selected criteria for the evaluation model and the management in the diagnosis of the current situation and the improvement of the model.

\section{Results of the systemic analysis}

This section presents the result of the detailed analysis carried out in each of the 24 scientific articles that compose the bibliographic portfolio considering the constructivist vision applied in each of the analysis lenses: (i) theoretical filiation; (ii) context singularity; (iii) process of identification of the criteria; (iv) measurement methods (scales); (v) integration of scales (by reference levels); and, (vi) management (diagnosis and improvement).

\subsubsection{Analysis lens 1: theoretical filiation}

The performance evaluation on the degree of agility in the agile software development process, according to a constructivist perspective, considers that the evaluation criteria should be alignment with the decision maker's perception according to his goals, values and preferences (Keeney, 1996). Through this lens of analysis, it is possible to present how the other authors of the selected articles position themselves regarding theoretical filiation.

Of the articles previously selected, as for the lens of theoretical filiation, one group of articles was classified as normativist and another as prescriptivist. That is, no publications relevant to the topic with a descriptivist or constructivist view of the world were identified.

It is classed as normativist those who share the same goals, constructing universal models, without considering the preferences and values of the decision maker, understanding the organizations as equals, in the same degree of maturity (Dias \& Tsoukiàs, 2003; Roy, 1993). As an example, the research of Qumer and Henderson-Sellers (2008b) based on the 4-DAT (Dimensional Analytical Tool) model helps to define the degree of agility that can be adopted by any company, also contemplating the following articles: Olszewska, Heidenberg, Weijola, Mikkonen, 
and Porres (2016), Gren et al. (2015), Gandomani and Nafchi (2014), Tarhan and Yilmaz (2014), Lee and Xia (2010), Diebold, Theobald, Wahl, and Rausch (2019), Tam et al. (2020), Miranda and Bourque (2010), Patel and Ramachandran (2009), Chow and Cao (2008), Qumer and Henderson-Sellers (2008a), (Ozcan-Top, 2019), Sidky et al. (2007), Paulk (2001), Paulk, Curtis, Chrissis, and Weber (1993) and Boehm (1988).

In a prescriptivist filiation, one should consider the particularities of the company, analyzing the managers' interests according to the context, respecting their preferences and then prescribing the evaluation criteria, constructing a personalized form of the evaluation model, consulting its stakeholders and prescribing a solution in the vision of the external facilitator (Dias \& Tsoukiàs, 2003; Roy, 1993). In this filiation stand out the researches of Fontana et al. (2015), Jalali et al. (2014), Srivastava et al. (2020), Choras et al. (2020), McCaffery et al. (2007), Alahyari et al. (2017) and Basili and Rombach (1988), who mention that the developed model is exclusively adapted to each particular company, each with its own objective.

In prescriptivist epistemology the decision maker is able to verbally explain his intentions and there is no need or interest in expanding his understanding of the context. In this approach the researcher makes use of the knowledge generated to understand the situation and prescribe a solution.

On the other hand, in constructivism, the decision maker recognizes that he needs to expand his understanding of the context and change his discourse as the model is conceived and presented to him (de Azevedo et al., 2012; Lacerda et al., 2014; Marafon et al., 2015; Roy, 1993; Tsoukiàs, 2008).

The prescriptivist theoretical filiation is characterized by an endogenous rationality, that is, with influence of external factors, consistent with the decision, while the constructivist filiation recognizes and accepts the limited rationality, since it understands the learning process coherent with the process decision-making (Tsoukiàs, 2008).

Recognizing, therefore, that learning is intrinsic characteristic of both constructivism and the agile methods applied to the software development process, plus the result of the evaluation of this first lens of analysis, one observes research opportunities in the constructivist epistemological view by recognizing and respecting the peculiarities of the researcher, allowing the personalized construction of the evaluation model to be used by a single company, but whose method for constructing the model can be replicated to others, generating and expanding the knowledge in the decision maker considering its objectives, values and preferences during this construction (Dias \& Tsoukiàs, 2003; Landry, 1995; Roy, 1993).

\subsubsection{Analysis lens 2 : singularity}

In the light of constructivism, this article considers the singularity of each 
company as a decision aiding, recognizing the values and preferences of the decision maker and the specific resources/competences of a given context at the moment of decision making. Evaluating this lens of analysis, it was identified how the authors of the established articles were positioned as to the recognition of the singularity in the companies (de Azevedo et al., 2012; Ensslin et al., 2013; Lacerda et al., 2014; Roy, 1993)

Under the lens of singularity, articles that do not recognize the singularity, ignoring the decision maker and the singularity of the company, emphasizing generic criteria in the literature, mathematical and/or statistical models as in the research of Gren et al. (2015), focusing on the decision-making approach and restricting the objective part, are: Olszewska et al. (2016), Gandomani and Nafchi (2014), Diebold et al. (2019), Tam et al. (2020), Tarhan and Yilmaz (2014), Lee and Xia (2010), Srivastava et al. (2020), Miranda and Bourque (2010), Patel and Ramachandran (2009), Chow and Cao (2008), Qumer and Henderson-Sellers (2008a, 2008b), Sidky et al. (2007), Paulk (2001), Ozcan-Top and Demirors (2019), Paulk et al. (1993), Boehm (1988).

The authors thus classified as not recognizing such singularity, consider that all organizations are identical, thus leading to the understanding that criteria, scales, and reference levels are the same for all, using a universal approach.

On the other hand, there are authors who recognize the singularity paradigm and the singularity of decision aiding of each company, understanding that the adopted criteria are specific to the decision maker that is part of the context, whose knowledge originates from the subject or the relationship between object-subject: Fontana et al. (2015), Jalali et al. (2014), McCaffery et al. (2007), Alahyari et al. (2017), Choras et al. (2020) and Basili and Rombach (1988).

The importance of the singularity to the implementation of the agility concept is made by understanding that the different definitions of this construct generate inaccuracies and inconsistencies in the practice of managing software development projects, also impacting performance evaluation. In a recent research, Edivandro Carlos Conforto, Amaral, da Silva, Di Felippo, and Kamikawachi (2016) identified a total of 59 definitions for the term agility, confirming its subjectivity, and its perceptive character (Gandomani \& Nafchi, 2014; Qumer \& Henderson-Sellers, 2008a).

Therefore, based on this lens of analysis, it is proposed to have a research that recognizes the singularity, recognizing values and preference of the decision maker in the context, given that most scientific research identified as universal models.

\subsubsection{Analysis lens 3: identification process}

This analysis lens aims to indicate the instruments used for the identification of the performance evaluation criteria accepted by 
the authors related in the bibliographic portfolio.

Most authors cite that the criteria were identified through scientific literary review, as in the case of the work developed by Patel and Ramachandran (2009) when constructing an evaluation model based on the practices of the agile software development process, modified and customized from the CMMI (Capability Maturity Model Integration) reference model. Other researches with emphasis in the literature are: Olszewska et al. (2016), Gren et al. (2015), Lee and Xia (2010), Miranda and Bourque (2010), Diebold et al. (2019), Tam et al. (2020), Chow and Cao (2008), Qumer and Henderson-Sellers (2008a, 2008b), McCaffery et al. (2007) and Sidky et al. (2007), Paulk (2001), Paulk et al. (1993).

In addition to identification in the literature, Fontana et al. (2015), Gren et al. (2015), Gandomani and Nafchi (2014), Jalali et al. (2014), Choras et al. (2020), Tarhan and Yilmaz (2014), Alahyari et al. (2017), Lee and Xia (2010), Srivastava et al. (2020), Patel and Ramachandran (2009), Chow and Cao (2008) and McCaffery et al. (2007) also used questionnaires and/or interviews, while Sidky et al. (2007) conducted meetings to identify and validate the criteria. Ozcan-Top and Demirors (2019) rely to experts in order to identify aspects to measure the maturity level of an agile process.

It was observed only two related items in the portfolio that did not clearly address the way of identifying the evaluation criteria, from the authors Basili and Rombach (1988) and Boehm (1988), but convey the understanding of having meetings with decision makers and the like.

As can be observed, most articles in the bibliographic portfolio work with criteria from the literature, indicating that the decision maker has no responsibility for the criteria for having been obtained externally, from validated and legitimized universal models. In contrast, it is possible to use agile values that emphasize people instead of processes and documents, undoubtedly providing opportunities for the development of a process that incorporates the values and preferences of the decision maker, recognizing and valuing human perception (Keeney, 1996).

\subsubsection{Analysis lens 4: measurement form}

After identifying the performance criteria that the company will use to assess agility during the software development process by adopting agile methods, it is significant to analyze how the evaluation scales are constructed and used for each of the specified objectives (Keeney, 2009; Lacerda et al., 2014).

In the portfolio analysis, it was noticed that the majority of the authors made use of the Likert scale, as Chow and Cao (2008) when adopting a scale of 7 points. It is a type of psychometric response scale frequently used in questionnaires that allows respondents to indicate the level of attraction for a particular issue (Lacerda et al., 2014). Other articles in 
the portfolio are: Fontana et al. (2015), Srivastava et al. (2020), Tam et al. (2020), Gren et al. (2015), Gandomani and Nafchi (2014), Jalali et al. (2014), Lee and Xia (2010), Patel and Ramachandran (2009), Qumer and Henderson-Sellers (2008a, 2008b), Ozcan-Top and Demirors (2019) and McCaffery et al. (2007).

Because of the limitations of the Likert scale, such as its ambiguity in being considered good for its practical and rapid application, but bad for the lack of clear definition, other authors have opted for the application of ordinal scales identified in the articles by Tarhan and Yilmaz (2014), Lee and Xia (2010), Alahyari et al. (2017), Choras et al. (2020), Qumer and Henderson-Sellers (2008a) and Paulk et al. (1993), with the purpose of defining the reference levels. Other authors did not address the use of scales to measure the evaluation criteria: Olszewska et al. (2016), Miranda and Bourque (2010), Diebold et al. (2019), Sidky et al. (2007), Paulk (2001), Basili and Rombach (1988) and Boehm (1988), although in Sidky's work there are implicit indications of the use of the Likert scale.

In relation to the ordinal scales, which make it possible to clarify the order of preference of a criterion, besides allowing the advance to cardinal scales, it is possible to glimpse its usefulness in performance evaluate of the degree of agility in the software development process, under a constructivist approach, because these scales respect the individual preferences and the priorities of the decision makers involved in the context (L. Ensslin et al., 2014; Keeney, 1996, 2009).

In this lens of analysis, scientific researches that present ordinal scales to performance evaluate in the agile software development process, generating research opportunity to evaluate the degree of agility through these scales are minimal.

\subsubsection{Analysis lens 5: integration of scales}

The present analysis lens assesses whether the articles that compose the bibliographic portfolio perform the integration of scales, either to order or prioritize the established evaluation criteria.

Most of the articles related in the research do not discuss the question of integrating ordinal scales into cardinal, which would allow comparisons that cannot be performed with ordinal scales: Olszewska et al. (2016), Diebold et al. (2019), Tam et al. (2020), Choras et al. (2020), Fontana et al. (2015), Gren et al. (2015), Gandomani and Nafchi (2014), Jalali et al. (2014), Tarhan and Yilmaz (2014), Patel and Ramachandran (2009), Chow and Cao (2008), Qumer and Henderson-Sellers (2008a, 2008b), McCaffery et al. (2007), Sidky et al. (2007), Paulk (2001), Paulk et al. (1993), Basili and Rombach (1988) and Boehm (1988).

Despite this, in the research by McCaffery et al. (2007) was presented a BSC (Balance Scorecard) for integration of the criteria. Besides this, in the article of Lee and 
Xia (2010) there are indications of a possible integration between the scales. The research of Alahyari et al. (2017), the authors use 100dollar method (Leffingwell and Widrig, 2003) for this integration. Ozcan-Top and Demirors (2019) propose three levels similar to maturity models to integrate their model. Srivastava et al. (2020) uses ANP process (Saaty, 2004), that is, there is known limitation called rank reversal order.

Once the performance evaluation has been performed and the overall results have been obtained, there are innumerable forms of improvements in which the integration of scales and the management lens presented below will make it possible to identify which evaluation criterion is most relevant to the context and, therefore, it presents greater contribution to obtain the agility. Thus, when considering the limited rationality, recognizing that the variables are not clear, as well as the limitations of resources, the integration of scales becomes paramount for the understanding of the context, actions of improvement and application of reference levels for comparison of the criteria, resulting in research opportunities due to the lack of cases as observed in the portfolio.

\subsubsection{Analysis lens 6: management}

The analysis lens that deals with the management was divided in two approaches: (i) diagnosis of the current situation; and, (ii) improvement. Regarding the diagnosis, considering the bibliographic portfolio, the scientific articles that diagnosed the current situation through qualitative instruments were: Olszewska et al. (2016), Choras et al. (2020), Fontana et al. (2015), Gren et al. (2015), Jalali et al. (2014), Tarhan and Yilmaz (2014), Srivastava et al. (2020), Lee and Xia (2010), Patel and Ramachandran (2009), Chow and Cao (2008), Ozcan-Top and Demirors (2019) and McCaffery et al. (2007). Alahyari et al. (2017) use interviews in order to identify barriers to deliver value in agile process.

Gandomani and Nafchi (2014), Miranda and Bourque (2010), Qumer and Henderson-Sellers (2008a, 2008b), Sidky et al. (2007), Tam et al. (2020), Choras et al. (2020), Paulk (2001), Paulk et al. (1993), Diebold et al. (2019), Basili and Rombach (1988) and Boehm (1988), although there is the understanding by the authors of this research that some of the authors related here have used qualitative instruments but not explicitly stated.

In relation to the improvement, prevails the articles that did not address preventive and/or corrective actions of performance: Fontana et al. (2015), Gren et al. (2015), Gandomani and Nafchi (2014), Jalali et al. (2014), Tarhan and Yilmaz (2014), Tam et al. (2020), Lee and Xia (2010), Miranda and Bourque (2010), Patel and Ramachandran (2009), Chow and Cao (2008), Qumer and Henderson-Sellers (2008a, 2008b), Alahyari et al. (2017), McCaffery et al. (2007), Sidky et al. (2007), Paulk (2001), Basili and Rombach (1988) and Boehm (1988). 
Studies related in the portfolio considered a program of continuous improvement, but not detailed in its work, although it shows similarity to the PDCA (Plan Do Check Act) cycle to evaluate the current situation and take actions to improve the evaluation criteria: Paulk et al. (1993) and Diebold et al. (2019). Aiming at further improvement, the research of Olszewska et al. (2016) only suggests continuous monitoring, applying a model of metrics presented by them. Ozcan-Top and Demirors (2019) use the approach of maturity models in order to improve processes. Srivastava et al. (2020) use ANP process and show a way to improve the process with ordinal scales.

With emphasis on the presented results, majority of them explicitly presented the diagnosis, allowing to identify the current situation of the established criteria. This indicator also shows that there are research opportunities involving qualitative instruments that allow the reflection and the construction of the knowledge in the decision maker, allowing the visualization of new actions. It is also added the opportunity to use a collection instrument at least ordinal regarding the application of the scales, since it was not identified in the portfolio.

It was possible to observe that the vast majority of the research presented in the portfolio does not contribute to an improvement of the context in focus, not allowing to the decision makers a better understanding about the current situation. Once the integration of scales is made, allowing the overall evaluation, it is possible to present to the decision maker which of the criteria it represents as being the most relevant to its specific context and, therefore, to present improvement actions and to broaden its understanding of what consequences of their actions. Therefore, new research opportunities are exposed in this lens of analysis.

\subsubsection{Synthesis of research opportunities}

For more detail, from the systemic analysis of the articles related to the bibliographic portfolio, the Figure 5 presents the research opportunities based on each analysis lens. 
Figure 5 - Research opportunities

\begin{tabular}{|c|c|}
\hline Analysis Lens & Analysis - Research Question \\
\hline 1: Theory filiation & $\begin{array}{l}\text { How to develop a performance evaluation model in agility in the } \\
\text { software development process that considers the values and preferences } \\
\text { of decision makers as it builds and enhances knowledge about the } \\
\text { context in these decision makers? }\end{array}$ \\
\hline 2: Singularity & $\begin{array}{l}\text { How to develop a performance evaluation model in agility in the } \\
\text { software development process that considers the subjectivity of the } \\
\text { decision makers as to their perception of agility? }\end{array}$ \\
\hline 3:Identification process & $\begin{array}{l}\text { How to develop a performance evaluation model in agility in the } \\
\text { software development process, allowing to identify and thus } \\
\text { contemplate evaluation criteria that consider the values and preferences } \\
\text { of the decision makers, as well as the singularity of the company in the } \\
\text { inserted context generating competitive advantage? }\end{array}$ \\
\hline 4:Measurement form & $\begin{array}{l}\text { How to develop a performance evaluation model in agility in the } \\
\text { software development process that use scales that impose reference } \\
\text { levels? }\end{array}$ \\
\hline 5:Integration of scales & $\begin{array}{l}\text { How to develop a performance evaluation model in agility in the } \\
\text { software development process that use scales that besides assigning } \\
\text { reference levels, allow the integration of indicators? }\end{array}$ \\
\hline 6:Management - Diagnosis & $\begin{array}{l}\text { How to qualitatively analyze the current situation of the company, } \\
\text { allowing to identify and organize its objectives, respecting the } \\
\text { singularity and defining and prioritizing its actions based on the } \\
\text { preferences of the decision makers? }\end{array}$ \\
\hline 6: Management - Improvement & $\begin{array}{l}\text { Once the performance evaluation model in agility has been applied in } \\
\text { the software development process, how can it generate knowledge } \\
\text { among decision makers to outline actions that improve their } \\
\text { objectives? }\end{array}$ \\
\hline
\end{tabular}

Source: Authors.

\section{Conclusions and research opportunities}

Considering the relevance given to the topic and the development of academic research, after the systemic analysis of the portfolio that gives scientific background and evaluating the proposed analysis lenses, it is possible to identify important niches of study and to create research opportunities, highlighting in these the difficulty of measuring something ambiguous, such as agility, and the possibility of indicating the 
degree of agility employed in a software development process.

It is observed the search for good practices in the area of software development referring to the agile methods results that add efficiency and that are aligned with the values of the evaluated company, allowing managers to make decisions faster. Thus, the authors of this research understand that the evaluation of agility is fundamental to improve the process of software development using agile methods, regardless of the method chosen, supporting the manager with a decision aiding approach.

Considering the analysis lenses presented, in evaluation to the articles most relevant to the topic, it is proposed to have a research that recognizes the singularity, recognizing values and preferences of the decision maker, in a constructivist perspective, considering the importance of having specific and personalized evaluation criteria for that the model can be legitimized, seeking not only information external to the context evaluated, that is, criteria based on literature, since they ignore the knowledge of the decision maker, but mainly respecting their preferences.

Still based on the lenses, a research opportunity was identified applying ordinal and cardinal scales, making it possible to identify which evaluation criterion is most relevant to the context, considering the limitation of the ordinal scales in comparing the criteria.

It is important to highlight that no article in this qualified scientific portfolio derived its decision support systems in improving agile project development processes from the company's objectives and evaluation criteria. The methods researched and proposed in the articles cited in the bibliographic portfolio have generic organizational objectives, such as reducing deadlines, failures and costs in software development. This finding has already been criticized in the general area of project management (Williams, 2005; Senhar and Dvir, 2007; Pollack, 2007) and solutions have been proposed for this field of knowledge (Roy, 1993; Senhar, 2004; Pich, Loch and Meyer, 2002; Lacerda et al., 2011).

With regard to the field of agile methods, it is possible to infer some hypotheses for this similarity. However, just as project management from hard operational research has influenced the field of knowledge for decades and has coined assumptions and assumptions only now challenged by an economy based on human intellect and creativity, the agile movement originated from programmers of origin and technical backgrounds. And even today, this technical community conflicts with project managers who still have mechanistic epistemological backgrounds. Thus, it can be assumed that the agile movement has grown strongly in the bases of software companies, and often with parallel development processes.

Thus, an important research gap emerges, revealed and proposed in this paper, of developing models to support constructivist decision-making in order to integrate unique 
strategic objectives for each organization, its project management processes and align agile practices in favor of these objectives.

This general challenge is unfolded in the research opportunities presented in Figure 5 , based on each analysis lens from the systemic analysis of the articles related to the bibliographic portfolio of this paper.

It was observed in the portfolio that the performance evaluation to measure agility in the context of software development, with the adoption of agile methods, has focused practically on critical success factors and on inflexible models that rank in maturity levels, but without clearly evaluating how much agility is employed. In other words, companies seek to improve software development processes, seek agility through the application of agile methods, but no significant evidence has been identified for a performance evaluation model that records an agility indicator considering the objectives and evaluation criteria of the company through its decision-makers.

Finally, few studies focused on agility evaluation were identified, considering evaluation tools and techniques involving scopes and limited applications, generating opportunities and motivations to conduct research in a constructivist approach to performance evaluation regarding agility in the software development process, to that one can perceive the degree of agility.

\section{Acknowledgments}

This work was carried out with support from $\mathrm{CNPq}$, National Council for Scientific and Technological Development - Brazil and with support from the Coordination for the Improvement of Higher Education Personnel Brazil (CAPES) - Financing Code 001.

\section{References}

Afonso, M. H. F., de Souza, J. V., Ensslin, S. R., \& Ensslin, L. (2012). Building knowledge on themed research: using the proknow-c process to find literature on sustainable development. Revista de Gestão Social e Ambiental, 5(2), 47-62. DOI: $10.5773 /$ rgsa.v5i2.424

Baines, T., Lightfoot, H., Williams, G. M., \& Greenough, R. (2006). State-of-the-art in lean design engineering: a literature review on white collar lean. Proceedings of the Institution of Mechanical Engineers, Part B: Journal of Engineering Manufacture, 220(9), 1539-1547.DOI: 10.1243/09544054JEM613

Basili, V. R., \& Rombach, H. D. (1988). The TAME project: Towards improvementoriented software environments. IEEE Transactions on software engineering, 14(6), 758-773. DOI:10.1109/32.6156

Behn, R. D. (2003). Why measure performance? Different purposes require different measures. Public administration review, 63(5), 586-606. DOI:10.1111/15406210.00322

Beck, K., Beedle, M., van Bennekum, A., Cockburn, A., Cunningham, W., Fowler, M., Grenning, J., Highsmith, J., Hunt, A., Jeffries, R., Kern, J., Marick, B., Martin, R. C., Mellor, S., Schwaber, K., Sutherland, J. $\&$ Thomas, D. (2001). Manifesto for agile software development. 2001. URL: http://www.agilemanifesto.org. 
Boehm, B. W. (1988). A spiral model of software development and enhancement. Computer, 21(5), 61-72. DOI: 10.1109/2.59

Calvetti, E. S., de Oliveira Lacerda, R. T., \& Bernardes, M. L. (2019). Um estudo bibliométrico sobre avaliação de desempenho no processo de desenvolvimento ágil de software sob a perspectiva do construtivismo. Revista Brasileira de Gestão e Inovação (Brazilian Journal of Management \& Innovation), 6(3), 1-28. DOI: 10.18226/23190639.v6n3.01

Casarin, H. d. C. S., \& Casarin, S. J. (2011). Scientific research: from theory to practice. Curitiba: Ibpex.

Cockburn, A., (2002) Agile software development. Boston, MA: Pearson Education, Inc;

Chow, T., \& Cao, D.-B. (2008). A survey study of critical success factors in agile software projects. Journal of Systems and Software, 81(6), 961-971. DOI: 10.1016/j.jss.2007.08.020

Conforto, E. C., \& Amaral, D. C. (2016). Agile project management and stage-gate modelA hybrid framework for technology-based companies. Journal of Engineering and Technology Management, 40, 1-14. DOI: 10.1016/j.jengtecman.2016.02.003

Conforto, E. C., Amaral, D. C., da Silva, S. L., Di Felippo, A., \& Kamikawachi, D. S. L. (2016). The agility construct on project management theory. International Journal of Project Management, 34(4), 660-674. DOI: 10.1016/j.ijproman.2016.01.007

Cohn, M., (2009) Succeeding with Agile: Software Development using Scrum., , Boston, MA: Addison-Wesley Professional;

Crawford, L., \& Pollack, J. (2004). Hard and soft projects: a framework for analysis. International Journal of Project Management, 22(8), 645-653. DOI: 10.1016/j.ijproman.2004.04.004 da Rosa, I. O., Ensslin, L., \& Ensslin, S. R. (2011). A conceptual vision of enterprise risk management models. Revista Eletrônica de Ciência Administrativa, 10(2), 124. DOI: https://doi.org/10.5329/RECADM.2011100 2009

de Azevedo, R. C., Lacerda, R. T. O., Ensslin, L., Jungles, A. E., \& Ensslin, S. R. (2012). Performance measurement to aid decision making in the budgeting process for apartment-building construction: case study using MCDA-C. Journal of Construction Engineering and Management, 139(2), 225235. DOI: 10.1061/(ASCE)CO.19437862.0000587

de Oliveira, L. V., Lacerda, R. T. O., Fiates, G. G. S., \& Ensslin, S. R. (2016). Decision aid in project management: a bibliometric analysis. Gestão e Projetos: GeP, 7(1), 95113. DOI: $10.5585 /$ gep.v7i1.329

Dias, L. C., \& Tsoukiàs, A. (2003). On the constructive and other approaches in decision aiding. Paper presented at the Proceedings of the 57th meeting of the EURO MCDA working group. to appear.

Diebold, P., Theobald, S., Wahl, J., \& Rausch, Y. (2019). Stepwise transition to agile: From three agile practices to Kanban adaptation. Journal of Software-Evolution and Process, 31. DOI:10.1002/smr.2167

Dingsøyr, T., Nerur, S., Balijepally, V., \& Moe, N. B. (2012). A decade of agile methodologies: Towards explaining agile software development. In: Elsevier.

Ensslin, L., Ensslin, S. R., \& de Souza, M. V. (2014). Product portfolio management in industry: status quo. Revista Produção Online, 14(3), 790-821. DOI: 10.14488/1676-1901.v14i3.1050

Ensslin, L., Ensslin, S. R., Lacerda, R. T. O., \& Tasca, J. E. (2010). ProKnow-C, knowledge development process-constructivist. Processo técnico com patente de registro pendente junto ao INPI. Brasil, 10(4), 2015. 
Ensslin, S. R., Back, F., Ensslin, L., \& Lacerda, R. T. O. (2013). Improved decision aiding in human resource management: a case using constructivist multi-criteria decision aiding. International Journal of Productivity and Performance Management, 62(7), 735-757. DOI: 10.1108/IJPPM-042012-0039

Ensslin, S. R., Ensslin, L., Lacerda, R. T. O., \& Matos, L. d. S. (2013). Disclosure of the state of art of the topic performance measurement in public utilities regulation according to the researcher's perception. Gestão Pública: Práticas e Desafios, 4(1).

Fontana, R. M., Meyer, V., Jr., Reinehr, S., \& Malucelli, A. (2015). Progressive Outcomes: A framework for maturing in agile software development. Journal of Systems and Software, 102, 88-108. DOI:10.1016/j.jss.2014.12.032

Gandomani, T. J., \& Nafchi, M. Z. (2014). Agility assessment model to measure Agility degree of Agile software companies. Indian Journal of Science and Technology, 7(7), 955-959.

doi:http://www.ijcsi.org/papers/IJCSI-9-4-3127-133.pdf;

Gren, L., Torkar, R., \& Feldt, R. (2015). The prospects of a quantitative measurement of agility: A validation study on an agile maturity model. Journal of Systems and Software, 107, 38-49.

DOI:10.1016/j.jss.2015.05.008

Jalali, S., Wohlin, C., \& Angelis, L. (2014). Investigating the applicability of Agility assessment surveys: A case study. Journal of Systems and Software, 98, 172-190. DOI:10.1016/j.jss.2014.08.067

Keeney, R. L. (1996). Value-focused thinking: Identifying decision opportunities and creating alternatives. European journal of operational research, 92(3), 537-549. DOI: 10.1016/0377-2217(96)00004-5

Keeney, R. L. (2009). Value-focused thinking: A path to creative decisionmaking: Harvard University Press.
Kennerley, M., \& Neely, A. (2002). A framework of the factors affecting the evolution of performance measurement systems. International journal of operations $\&$ production management, 22(11), 12221245. DOI: $10.1108 / 01443570210450293$

Lacerda, R. T. O., Ensslin, L., \& Ensslin, S. R. (2014). Research opportunities in strategic management field: a performance measurement approach. International Journal of Business Performance Management, 15(2), 158-174. DOI: 10.1504/IJBPM.2014.060165

Lacerda, R. T. O., Klein, B. L., Fulco, J. F., Santos, G., \& Bittarello, K. (2017). Integração inovadora entre empresas incubadas e universidades para geração contínua de vantagens competitivas em ambientes dinâmicos. Navus-Revista de Gestão e Tecnologia, 7(2), 78-96. DOI: 10.22279/navus.2017.v7n2.p78-96.497

Landry, M. (1995). A note on the concept of'problem'. Organization studies, 16(2), 315-343.

Lee, G., \& Xia, W. (2010). Toward agile: an integrated analysis of quantitative and qualitative field data. Management Information Systems Quarterly, 34(1), 7. DOI: 10.1142/9789814295628_0006

Mahnič, V., \& Zabkar, N. (2008). Using COBIT indicators for measuring scrumbased software development. Wseas transactions on computers, 10(7), 16051617.

Marafon, A. D., Ensslin, L., Lacerda, R. T. O., \& Ensslin, S. R. (2012). R\&D management performance evaluation - systematic literature review. $P \& D$ em Engenharia de Produção, 10(2), 171-194.

Marafon, A. D., Ensslin, L., Lacerda, R. T. O., \& Ensslin, S. R. (2015). The effectiveness of multi-criteria decision aid methodology: A case study of R\&D management. European Journal of Innovation Management, 18(1), 86-109. DOI: 10.1108/EJIM-10-2013-0106 
McCaffery, F., Taylor, P. S., \& Coleman, G. (2007). Adept: A unified assessment method for small software companies. IEEE

Software, 24(1), 24-31.

DOI:10.1109/MS.2007.3

Melnyk, S. A., Bititci, U., Platts, K., Tobias, J., \& Andersen, B. (2014). Is performance measurement and management fit for the future? Management Accounting Research, 25(2), 173-186. DOI:

https://doi.org/10.1016/j.mar.2013.07.007

Miranda, E., \& Bourque, P. (2010). Agile monitoring using the line of balance. Journal of Systems and Software, 83(7), 1205-1215. DOI:10.1016/j.jss.2010.01.043

Misra, S. C., Kumar, V., \& Kumar, U. (2009). Identifying some important success factors in adopting agile software development practices. Journal of Systems and Software, 82(11), 1869-1890. DOI:

10.1016/j.jss.2009.05.052

Nierstrasz, O., Lungu, M., (2012) Agile software assessment (Invited paper)., , Paper presented at the 20th IEEE International Conference on Program Comprehension, ICPC 2012, Passau;

Olszewska, M., Heidenberg, J., Weijola, M., Mikkonen, K., \& Porres, I. (2016). Quantitatively measuring a large-scale agile transformation. Journal of Systems and Software, 117, 258-273.

DOI:10.1016/j.jss.2016.03.029

Patel, C., \& Ramachandran, M. (2009). Story card Maturity Model (SMM): A process improvement framework for agile requirements engineering practices. Journal of Software, 4(5), 422-435. DOI: 10.4304/jsw.4.5.422-435

Paulk, M. C. (2001). Extreme programming from a CMM perspective. IEEE Software, 18(6), 19-26. DOI: 10.1109/52.965798

Paulk, M. C., Curtis, B., Chrissis, M. B., \& Weber, C. V. (1993). Capability maturity model, version 1.1. IEEE Software, 10(4), $18-27$.

Petersen, K., \& Wohlin, C. (2011). Measuring the flow in lean software development. Software: Practice and experience, 41(9), 975-996. DOI:

https://doi.org/10.1002/spe.975

Qumer, A., Henderson-Sellers, B., McBride, T., (2007) Agile adoption and improvement model., , Paper presented at the 4th European and Mediterranean Conference on Information Systems, EMCIS; Valencia;

Qumer, A., \& Henderson-Sellers, B. (2008a). An evaluation of the degree of agility in six agile methods and its applicability for method engineering. Information and software technology, 50(4), 280-295. DOI:10.1016/j.infsof.2007.02.002

Qumer, A., \& Henderson-Sellers, B. (2008b). A framework to support the evaluation, adoption and improvement of agile methods in practice. Journal of Systems and Software, 81(11), 1899-1919. DOI: 10.1016/j.jss.2007.12.806

Roy, B. (1993). Decision science or decisionaid science? European journal of operational research, 66(2), 184-203.

Rubin, K., Cohn, M., Williams, L., (2010) Comparative Agility (CA), http://comparativeagility.com/;

Sidky, A., Arthur, J., \& Bohner, S. (2007). A disciplined approach to adopting agile practices: The agile adoption framework. Innovations in Systems and Software Engineering, 3(3), 203-216. DOI:10.1007/s11334-007-0026-z

Soundararajan, S., Arthur, J.D., (2011) A structured framework for assessing the "goodness" of agile methods., , Paper presented at the 18th IEEE International Conference and Workshops on Engineering of Computer-Based Systems, ECBS 2011; Las Vegas, NV; 
Soundararajan, S., Arthur, J.D., Balci, O., (2012) A methodology for assessing agile software development methods., , Paper presented at the Agile Conference; Agile, Dallas, TX; (2010) Thoughtworks. Agile Assessments, , http://www.agileassessments.com/;

Spinellis, D., Agility drivers. (2011) IEEE Software., 28 (4);

Tarhan, A., \& Yilmaz, S. G. (2014) Systematic analyses and comparison of development performance and product quality of Incremental Process and Agile Process. Information and software technology, 56(5), 477-494. DOI:10.1016/j.infsof.2013.12.002
Tsoukiàs, A. (2008) From decision theory to decision aiding methodology. European journal of operational research, 187(1), 138-161. DOI: 10.1016/j.ejor.2007.02.039

Williams, L., (2012) What agile teams think of agile principles. Communications of the ACM., 55 (4), pp. 71-76 DOI: $10.1145 / 2133806.2133823$.

Williams, L., Rubin, K., Cohn, M., (2010) Driving process improvement via comparative agility assessment., , Paper presented at the Proceedings of the 2010 Agile Conference. 